\title{
A Review of Knowledge Hiding Behavior
}

\author{
Lu Bai \\ University of Science and Technology, Nanjing 210094, Jiangsu, China \\ *Corresponding author. Email: 280722153@qq.com
}

\begin{abstract}
In today's world, knowledge plays an increasingly prominent role in promoting the development of enterprises. In the knowledge age, organizational innovation lies in knowledge innovation, which relies on knowledge sharing. However, knowledge hiding behaviour is common in organizations, which hinders knowledge transfer and knowledge sharing, and finally affects organizational innovation. Therefore, knowledge hiding, as a new perspective in the field of knowledge management, has theoretical and practical significance. In this paper, the concept of knowledge hiding, influencing factors and current research status are sorted out to provide certain reference for future research.
\end{abstract}

Keywords: knowledge hiding, knowledge management, organizational innovation

\section{INTRODUCTION}

Through the overall review of the research progress in related fields, the existing research has accumulated some research results on the subject of knowledge hiding behaviour, but there are also some problems. The research on knowledge management at home and abroad shows that compared with the behaviour of knowledge hiding, the literature of knowledge management is large. In addition, in its many research topics, the study of knowledge sharing is one of the most important themes of knowledge management, the existing research confirms the important role of knowledge sharing in knowledge management and sustainable development of enterprises and in many ways, the multi-dimensional fully discusses the knowledge sharing, but research on barriers to knowledge sharing is still in its infancy. Therefore, research on knowledge sharing barriers and interventions based on the "reverse" perspective should also receive more attention. As the representative of this kind of "reverse" research, "knowledge hiding" has received the attention of the academic circle since it was proposed. Therefore, it is of great significance to actively promote the research on knowledge hiding behaviour.

\section{The Connotation of Knowledge Hiding Behaviour}

Although knowledge hiding, as an independent emerging concept, was proposed by Connelly and other scholars in 2012, its history has been long. Only in the early stage, relevant scholars did not treat it as an independent concept. On the contrary, researchers regarded it as the opposite of knowledge sharing. Some researchers regarded it as a kind of counterproductive or lazy behaviour. Connelly (2012) integrated and compared employees' behaviours such as knowledge storage behaviour, knowledge sharing behaviour, employee silence behaviour, cheating behaviour, impolite behaviour, social inhibition behaviour, aggressive behaviour and counterproductive behaviour in the workplace, and proposed this new concept.

The research on the behaviour of knowledge hiding started late in China, but some progress has been made. As for the concept of knowledge hiding behaviour, J.X. Li and J. Liu (2018) defined it as the behaviour that an individual in an organization intentionally conceals or deliberately conceals knowledge requests from colleagues [1]. According to W.L. Wang (2016), knowledge hiding behaviour refers to the intentional behaviour in the workplace where employees deliberately pretend to be stupid, conceal or refuse to provide knowledge requested by colleagues [2]. However, H.D. Zhao and Q. Xia (2019) believe that employees' deliberate concealment of knowledge requesters in the organization is knowledge concealment [3]. B. S. Zhang and Q.P. Zhang (2017) pointed out that knowledge hiding is subjective and intentional, but it is not necessarily negative, destructive or deceptive. It may be out of personal or organizational considerations, and knowledge hiding and knowledge sharing are not opposite behaviours [4].

We can find that although knowledge hiding research has made some important achievements, compared with other related research concepts in knowledge management, its research is still in its infancy. In particular, there are still some deviations in the definition of the concept of knowledge storage, knowledge hiding and knowledge retention. Therefore, before the follow-up study, it is necessary to define the behaviour of knowledge hiding so as to clarify the connotation and boundary of the behaviour.

\section{Discrimination of Related Concepts of Knowledge Hiding}

As the concept of knowledge hiding itself is formed gradually in the process of studying the problem of knowledge sharing, it is related to the concepts of knowledge hoarding, knowledge sharing deficiency, counterproductive work behavior, workplace aggression 
and workplace incivility to some extent, but it is completely different from other behaviours. The similarities and differences are summarized as follows.

\subsection{The Similarities and Differences between Knowledge Hiding and Knowledge Hoarding}

According to Hislop, knowledge hoarding represents the accumulation of knowledge that may or may not be Shared in the future. What they have in common is that knowledge hiding and knowledge hoarding are both ACTS of knowledge retention; The difference between the two lies in their different intentions and ways. Knowledge hiding is the intentional concealment of the requested knowledge, while knowledge hoarding is not necessarily the knowledge sought by others. Knowledge hoarding focuses on the accumulation of knowledge, regardless of whether it can be shared.

\subsection{Similarities and Differences between Knowledge Hiding and Lack of Knowledge Sharing}

Knowledge hiding not only means not sharing knowledge, but more importantly, knowledge hiding is a deliberate concealment and concealment of the knowledge sought by others. Knowledge hiding and knowledge sharing are not opposite concepts, but two different concepts. In terms of behaviour, the two concepts are similar, but the motivations behind knowledge hiding and the lack of knowledge sharing are quite different. Knowledge concealment may be caused by different reasons such as laziness, while lack of knowledge sharing may simply be caused by insufficient ability to share or poor knowledge transfer due to forgetting. To sum up, from its definition, knowledge hiding has its own characteristics that distinguish it from other behaviors, and it is an independent variable. First of all, knowledge hiding takes place in context specific, which is a one-to-one, questioner and responder inquiry situation. However, other behaviors have no specific situation, which can be individual-to-individual, individual-to-group or intergroup. Secondly, knowledge hiding is intentional and deceptive. Finally, knowledge concealment has no intention of intentional harm. Knowledge concealment is a passive decision making behavior in the process of inquiry, which is to some extent to protect oneself or the organization, and does not intend to cause harm to others or the organization. However, counterproductive work behavior, workplace aggression and workplace incivility are behaviors that directly or indirectly cause intentional harm to the organization or individual.

\section{DIMENSION AND MEASUREMENT OF KNOWLEDGE HIDING BEHAVIOUR}

As for the dimension and measurement of knowledge hiding, the existing literature mainly has the following three different understandings.

First, based on the individual can take the perspective of knowledge hiding behaviour, Connelly et al. (2012) think that knowledge hidden is a three dimensional construct including playing dumb, evasive hiding and rationalized hiding. Using the inductive scale development method, they developed a tacit knowledge scale containing 12 items, and each dimension was composed of 4 items. A measurement example of playing dumb is "Pretending not to know something about it"; Evasive hiding of measurement items such as "I promise to help him/her, but in fact I will not take action". The measurement examples of rationalized hiding such as "Explain to the other person that I'm willing to tell, but someone doesn't want me to."

Secondly, from the perspective of individual behavioural intention, T. Zhao(2013)believes that knowledge hiding is a two-dimensional construct: active hiding and passive hiding. Active hiding refers to the strategy of delaying, pretending not to know or giving incomplete knowledge when hiding knowledge. The hiding behaviour is done out of one's own will. Passive concealment refers to the passive concealment of knowledge by individuals out of their own intentions, such as others' refusal to share. According to the results of exploratory factor analysis, T. Zhao(2013) adopted 5 measurement items to measure active hiding and 3 measurement items to measure passive hiding.

Finally, Peng(2013)considers knowledge hiding as a special form of knowledge workers' counterproductive production behaviour, and considers knowledge hiding as a unidimensional construct, and develops a measurement scale containing three items :(1) hiding useful information or knowledge from colleagues;(2) hiding innovative results from colleagues;(3) unwilling to convert personal experience and knowledge into organizational knowledge. From what has been discussed above, existing literature has not formed a unified understanding of the dimension and measurement of knowledge hiding, and relevant scholars respectively believe that knowledge hiding is a threedimensional, two-dimensional and one-dimensional construct. At present, the three-dimensional structure and measurement method of knowledge hiding proposed by Connelly et al. (2012) are generally recognized and adopted in the academic circle.

\section{RESEARCH PROGRESS OF KNOWLEDGE HIDING BEHAVIOUR}

\subsection{Foreign Research Progress}

In addition to the research on the definition and measurement of knowledge hiding, other academic researches on knowledge hiding mainly focus on the causal 
mechanism of knowledge hiding and the mediation effect test of knowledge hiding. Holten (2016) used the method of longitudinal study to find the interaction between employees' negative experience and knowledge hiding[5]. Zhao and Xia (2017) showed that the negative experience of being rejected by the workplace has a significant positive impact on employees' knowledge hiding[6]. Serenko and Bontis (2016) found that job insecurity could put employees under the threat of resource loss [7]. In order to avoid further loss of knowledge resources, knowledge owners hide more knowledge in the face of knowledge requests from colleagues, that is, job insecurity has a significant positive impact on employees' knowledge hiding. Anaza and Nowlin (2017) found that the opportunism of knowledge seekers positively affected the knowledge hiding of knowledge holders [8]. Akgun (2017) found in their research on software development teams that knowledge absorption capacity of knowledge seekers is an important reason for knowledge owners to hide knowledge [9].

\subsection{Domestic Research Progress}

Domestic studies started with R.P. Jiang and Y.M. He (2013), who initially verified the questionnaire on knowledge hiding (three dimensions) and discussed the influence of interpersonal factors (interpersonal distrust, negative reciprocity norms) and organizational factors (organizational atmosphere) on knowledge hiding. Aiming at employees' perception of the uncertainty of human capital property rights in the Internet industry, Y.M. He and R.P. Jiang (2016) studied the impact of the uncertainty of human capital income right, control right and use right on knowledge hiding.

In recent years, other domestic scholars have continued to explore the an preceding variables that affect knowledge hiding from different theoretical perspectives, and presented diversified research atmosphere: Q.P. Zhang and W. Pan(2016) explored the influence of perceived knowledge ownership and incentive atmosphere on knowledge hiding based on the theory of psychological ownership; based on the theory of resource protection, A.H. Huang and Z.S. Li (2016)found that job insecurity had a positive effect on knowledge hiding, which further affected employees' creativity. X.F. Zhang and Y.M. Xi (2016) discussed the influence mechanism of ethical leadership on employee knowledge hiding from the perspective of leadership style. X.Y. Sun and J.J. Chen (2016) analysed the causes of knowledge hiding by using the prisoner's dilemma and public goods dilemma theories based on the social dilemma theory [10].

\section{FUTURE REASEARCH PROSPECTS}

Although domestic scholars have begun to pay attention to the phenomenon of knowledge hiding and have made some research results, on the other hand, it should be noted that the current research is still far from enough in terms of scope and depth. Therefore, there is still much room for further exploration in the research of knowledge hiding. This paper believes that future research on knowledge hiding can focus on the following points:

On the one hand, further verification of knowledge hiding constructs is emphasized. At present, the research on knowledge hiding construct is not mature, and the definition of its concept involves a single scene (one-to-one), which cannot cover the knowledge hiding behaviour of other scenes in the work. For example, the hiding behaviour of one-to-many can be further explored in the future.

On the other hand, increase the research on the outcome variables generated by knowledge hiding. In terms of the antecedent variables and mediating variables of knowledge hiding, scholars have begun to carry out multi-dimensional research and exploration, but there are still few studies on the extent to which knowledge hiding behaviour affects individuals and organizations. This paper believes that only with the help of more data research, we can understand how much this kind of behaviour will hinder the organization's knowledge innovation activities, and further arouse the organization's attention.

\section{CONCLUSION}

Research on knowledge hiding behaviour at home and abroad shows that there is no unified consensus on the definition of knowledge hiding behaviour at home and abroad, and there are some disputes on the understanding of knowledge hiding behaviour. From the standpoint of behaviour of the object of study, further, the existing knowledge hidden behaviour research mainly concentrated in the generalization object type (no employee to distinguish) knowledge hidden behaviour, there is little focus in specific research object, explore, limits the refinement of knowledge hidden behaviour research object and the deep going research results. From the perspective of research content, the research on knowledge hiding mainly focuses on the causal mechanism of knowledge hiding. Among them, most researches only carry out qualitative discussion on its antecedents, or try to reveal the effect of 1-2 variables on knowledge hiding behaviour through empirical research methods. These researches often ignore the interaction between factors, and few scholars carry out integrated detailed analysis on the formation mechanism of knowledge hiding behaviour. Furthermore, studies on which factors will affect the occurrence of knowledge hiding behaviour and which combination of factors is more likely to produce knowledge hiding behaviour is still lacking. At present, there is no research on the formation mechanism of knowledge hiding behaviour based on configuration theory. 


\section{REFERENCES}

[1] J.X. Li, J. Li. (2018) Knowledge hiding behaviour: literature review and research prospect, Modern Management Science, No.302(05), 66-68. (In Chinese).

[2] W.L. Wang. (2016) Knowledge hiding behaviour in organizations: concepts and measurements, Shang, (20), 138-138. (In Chinese).

[3] H.D. Zhao, Q. Xia. (2019) Study on interpersonal distrust, negative emotion and knowledge hiding behaviour. Scientific Research Management, 40(8), 284292. (In Chinese).

[4] B.S. Zhang, Q.P. Zhang. (2017) Knowledge hiding behaviour antecedents of knowledge organization members based on grounded theory. Scientific and Technological Progress and Countermeasures, 34(10), 105-110. (In Chinese).

[5] Holten, A. L., Hancock, G. R., Persson, R. (2016). Knowledge hoarding: antecedent or consequent of negative acts? the mediating role of trust and justice. Journal of Knowledge Management, 20(2), 215-229.

[6] Zhao, H., Xia, Q. (2017). An examination of the curvilinear relationship between workplace ostracism and knowledge hoarding. Management Decision, 55(2), 331-346.

[7] Serenko, A., Bontis, N. (2016). Understanding counterproductive knowledge behaviour: antecedents and consequences of intra-organizational knowledge hiding. Journal of Knowledge Management, 20(6), 1199-1224.

[8] Anaza, N. A., Nowlin, E. L. (2017). Whatl"s mine is mine: a study of salesperson knowledge withholding \& hoarding behaviour. Industrial Marketing Management, S0019850117302614.

[9] Akgün, Ali E., Keskin, H., Ayar, H., Okunakol, Z. (2017). Knowledge sharing barriers in software development teams: a multiple case study in turkey. Kybernetes, 46(4), 603-620.

[10] X.Y. Sun, J.J. Chen. (2016) Research on knowledge hiding mechanism based on social dilemma theory. Chinese Collective Economy, (30) ,68-70. (In Chinese). 